\title{
Headlice eradication as everyday engagement with science: an analysis of online parenting discussions
}

\section{Introduction}

One fruitful branch of research in public understanding of science focuses on relatively mundane areas of everyday life, where we can explore a highly differentiated public engaging head-on with issues already significant to them that can (but may not) be framed in scientific terms. This approach encompasses such everyday areas as the interpretation of food or cosmetic labelling and advertising (such as Dodds et al. 2008; Eden 2011), the experience of living near potentially hazardous industrial facilities (Irwin et al. 1996), and lay medical expertise relating to specific medical conditions (for example Lambert and Rose 1996). Such research explores the extent to which issues are framed by a lay public in ways congruent with various forms of scientific and technical expertise. Instead of asking the public what they know about science, researchers working in this tradition take issues that already mean something to people and ask how what the public knows connects with science, often working from a discourse analytic perspective: Zeyer and Roth (2011), for example, study the diverse repertoires drawn on by Swiss students in their discussion of the environment. Researchers in this tradition have often drawn on interviews, alongside participant observation and surveys, to generate data on the ways in which diverse publics conceptualise issues. This paper continues this tradition of exploring science as one among many resources used by publics in interaction to frame everyday issues by using data derived from Internet forums, examining the various resources, including references to knowledge derived from scientific sources, which are used to conceptualise an everyday parenting problem and to justify actions. Internet-derived data offers the opportunity to explore how people draw on 
various resources in interactions between themselves, as a complement to studies which use data derived from interactions with researchers.

This paper conducts analysis of an online discussion forum to investigate how a particular group connect science with an everyday issue, as a new way of pursuing this long-standing interest in science studies. Because of the choice of research site, however, this project also inevitably engages with another set of ongoing debates concerning the nature of the expertise which is traded in online spaces, and thus offers the opportunity to connect recent debates about expertise on the Internet with concepts from the public understanding of science. Within sociology of medicine in particular there has been considerable interest in how peerto-peer or patient-to-patient lay groups construct novel forms of expertise which may bypass the control of formally credentialed experts in the domain at issue (Eysenbach 2008a; Eysenbach 2008b). As Miah and Rich (2008) describe, however, outcomes are complex, and the Internet has not led to a wholesale reconfiguration of medical expertise, despite initial anticipation that it might do so (Hardey 1999). Rather, as Leibing (2009) describes, online discussions among patients can involve an ongoing collective expression and appraisal of different forms of authority, including both formal scientific evidence and the authority that comes from describing one's own bodily experiences. Applying this framework to our understanding of public engagement with science offers some interesting prospects for a nuanced understanding of the situated processes that may give rise to the expression of scientific knowledge in everyday contexts.

The specific example I use to explore a lay public's contingent engagement with science is the problem of headlice. There is no single, universally agreed, medically approved, solution to headlouse infestation, and those affected may feel obliged to act because of social pressure 
and their own feelings of disgust but are placed in a position of judging between different forms of expertise and conflicting advice. I draw on public discussions in a popular online forum used by predominantly British parents to explore how these judgments are interactionally justified and the extent to which the interactions draw on conventionally understood scientific knowledge and credentialed sources of expertise. The focus, then, is not on what the public know about the science of headlice in itself, but on what if anything they choose to do with scientific knowledge in a context of interactions which position the parent as an expert.

Understanding how parents describe their judgments about treatment of headlice and what they portray as reliable sources could be of considerable practical use in designing public health campaigns, and improving interactions between schools, health visitors, doctors and parents on the issue. As O’Connor (2009) suggests, understanding of this kind of process could be a useful resource for official health communicators. In this context, knowing what objections might be raised to particular advised courses of action is important, and to that end I explore how representations of risk within this particular domain play out in interaction, and how they relate to identity as parent which is central to the narratives participants tell in this forum. Beyond its significance for designing better public health campaigns, however, this domain also offers a strategic site to contribute to our understanding of the nature of the situated everyday engagement with science, increasingly manifested in online interactions as much as in offline contexts.

In the next sections of the paper I outline in more detail the problem posed by headlice, and then describe the way in which a focus on headlice fits into an interest in everyday engagement with science in the Internet age. I then outline the data collection and analysis 
processes, and subsequently move on to describe key themes which emerged in the analysis of discussions about headlice on the online forums of the website Mumsnet. The paper concludes with a discussion of the significance of these themes in relation to the dynamics of public engagement with science on the Internet and in relation to Mumsnet as a very specific form of "public".

\section{Headlice eradication and parenting}

Estimates of the prevalence of headlice vary (Falagas et al. 2008), but infection rates have been estimated at 37\% of children per year in the UK in one survey (Harris et al. 2003), the majority of UK children during their school career will either suffer from headlice or be asked to check for headlice because a classmate is affected, and rates of infection appear to be increasing (Teale et al. 2008). Both children and parents can experience stigma, anxiety and shame when infestation occurs (Silva et al. 2008), particularly where the infestation is recurrent or prolonged (Gordon 2007). A responsible parent, at least in British settings, is expected to take action in the face of a child carrying headlice: Budd (2001) includes "Fails to get child medical treatment for head lice" as one of a list of "Functional parenting deficits" appropriate for use by professionals assessing parenting competence in child protection cases. This is, however, a highly culturally specific situation. One study in rural Nigeria suggested that headlice were prevalent but not perceived as a major problem, and knowledge about them was correspondingly low (Heukelbach and Ugbomoiko 2011). Attitudes have also changed over time, as has the role of institutions in addressing the problem. Many older British people remember a "nit nurse” who checked children's hair in school, but this practice has been discontinued for some time.

A Public Health Medicine Environmental Group report published in the UK in 2008 states that that headlice should be considered as a societal problem rather than an infectious disease, 
and notes that primary responsibility for treatment lies with parents, supported by appropriate professionals (Teale et al. 2008). There are however diverse competing treatments for headlice infestation, including chemical treatment and physical removal, and the picture is changing as new products come onto the market and as chemical resistances develop (Teale et al. 2008; Frankowski et al. 2010). Whilst the basic facts of the life cycle of the headlouse are fairly uncontroversial, modes of action of the various control agents may be less settled (Burgess 2009). Recent advice from the UK’s National Health Service acknowledges that the treatment picture is complex: "There is limited evidence to support the effectiveness of each treatment option recommended. No option is clearly superior or inferior to the others in terms of effectiveness and there are advantages and disadvantages for each method, and no method can guarantee success. The choice of a particular treatment strategy will depend on individual or parent preference, and success or failure with previous treatments” (CKS 2010).

Treating headlice successfully need not, in itself, require one to understand a complex degree of science. However, different means of treatment depend on different aspects of the biology of headlice, and in order to choose between options in an informed fashion and to operate the chosen solution effectively it may be very useful to know something of this biology. It may be useful, for example, to distinguish between systemic pesticides with neurotoxic action and silicone-based treatments that physically affect the ability of lice to acquire oxygen or excrete water, because lice are held to be less likely to become resistant to the latter (Burgess et al. 2005). In timing repeat treatments with pesticide or physical removal by combing it may help to know the length of the life cycle of lice in terms of egg hatching and maturation of larvae. It is also useful to know whether a given treatment is effective only on live lice, thus leaving potentially viable eggs behind in the hair. In taking practical control measures it is also useful to know how long lice can live away from a human host, and under what conditions. 
Headlice treatment is a heavily commercialised domain, with sales of over-the-counter remedies having been estimated in the UK at over $£ 25$ million for 2009/10

(Chemist+Druggist 2011). In survey-based studies parental knowledge has been deemed often inadequate for informed decisions and effective treatment (Silva et al. 2008;

Frankowski et al. 2010), and the knowledge level among relevant professionals has also been found to be variable (Olowokure et al. 2003). Many parents find the available remedies difficult to apply effectively (Parison et al. 2008). Stigma associated with headlice may also discourage people from asking advice from family and friends or professionals, and in contrast to many parenting dilemmas there can be a lack of support from older generations, since this generation encountered lower levels of headlice prevalence and a more heavily institutionalised treatment regime. The Internet vastly increases the potential information available to parents - a Google UK search on "head lice” in August 2010, mid-way through the sample period discussed in this paper, generated over one and a half million hits. We know very little, however, about how parents assess competing sources of information, and what, if any, difference the Internet makes to information actually used by parents to make or justify treatment choices. In this article I focus on one quite specific Internet context, the popular UK parenting forum Mumsnet (described in greater detail below under Methods). This forum offers a site to observe how parents directly affected by headlice discuss strategies for treatment and to find out how they draw on various sources of information, including other Internet sites, to do so.

\section{Science in everyday contexts}

Online discussions about treatment for headlice offer a useful strategic site to explore the deployment of scientific expertise in everyday situations. This interest in finding out how lay people engage with science as one among many resources which help them to make sense of their lives was influentially captured in the collection by Irwin and Wynne (1996) which 
assembled a diverse set of case studies of public understandings of science viewed as active processes of weaving together diverse resources. Subsequently Irwin’s (1995) work on citizen science continued to emphasize the existence of "contextual knowledges which are generated outside of formal scientific institutions” (Irwin 1995: xi). Wynne (1992; 2008) emphasises the need for a careful situationally-bounded analysis of public understanding of science, exploring the extent to which the setting constructs both the salient social identities for the discussion and the forms of knowledge and practices valued. Viewed in this perspective, representations of science by lay people will be both specific to and constitutive of particular occasions and interactions. As Wagner (2007) describes, representations of science will often be deployed when people interact with one another, and particularly will be used in the justification of actions.

The model of public understanding of science as a contextual phenomenon, fashioned by circumstances and constructed within specific interactions shaped the approach taken in this paper to the analysis of online discussions about headlice. It seemed likely that the culturally loaded social identity of parent would inform discussions around the eradication of headlice on Mumsnet and that science-based resources would be deployed alongside other forms of authority. With this in mind, I aimed to explore the forms of knowledge that held a local validity for the Mumsnet context, expecting that these would not simply be understood as simplified or misconstrued versions of formal scientific knowledge. This is not, as Wynne (2008) argues, to romanticize the public as having a somehow truer or better knowledge, but rather to acknowledge that in order to justify practical action issues may be framed in different ways to those offered by formal scientific and medical institutions (Wagner 2007).

This contextual model of the public understanding of science offers some useful tools for conceptualising developments in the dynamics of expertise contingent on the advent of the Internet. It has often been claimed that the Internet reconfigures relations of expertise. In the 
area of online health discussions in particular, Eysenbach (2008a; 2008b) suggests that the Internet increasingly promotes processes of apomediation, in which the role of formally appointed intermediaries such as healthcare professionals diminishes, and is replaced by mechanisms of filtering access to information sources which often include peers instead of formally credentialed experts. According to the perspectives on public understanding of science advanced by Wynne and Irwin, these apomediation processes might be expected to be both thoroughly shaped by and shaping of the interactional context. Similar points have been made by Leibing (2009) in describing the dynamic and collective evaluation of health information in a patient forum, although the connection to apomediation is not made explicit. In the online forums discussing headlice treatment we have the opportunity to see how parents act as mediators of public health messages for one another, observing the form which this contextualized advice takes and the identities and context which result. It will be of particular interest to look at how advice on courses of action and potential risks is made accountable in interactions between parents, and the extent to which external sources of verification are brought into play to support statements made in discussions.

In summary, this paper seeks to explore the following questions:

- What resources do participants in online discussions about headlice draw upon, and in particular what part does science play? What forms of authority are held to be convincing?

- What notions of risk do participants express, and how are these made accountable?

- To what extent are the resources advanced by participants in discussion bound to identities held to be salient in this specific context? 
- How do the dynamics of advice-giving in this context relate to conventional notions of medical and scientific expertise and/or to new relations of expertise such as apomediation that may be occasioned by the Internet.

\section{Data collection and analysis}

Mumsnet (www.mumsnet.com) was chosen as the focus for this study because of its status as currently the most prominent of the parenting web sites in the UK. The site offers access to a range of parenting-related content including information guides, product reviews, competitions, blogs and discussion forums, promoted as "by parents for parents”. Mumsnet reports more than one million visitors per month and enjoys both a high level of usage and a high level of visibility in the mass media as the go-to site for accessing the opinions of British parents (Gambles 2010; Pedersen and Smithson 2010). The use of online forums for sharing parenting advice and support is a significant and growing phenomenon (see for example Sarkadi and Bremberg 2004; Madge and O’Connor 2006; Daneback and Plantin 2008). A focus on parents as experts rather than reliance on institutionally-located experts is a feature of many of these sites, and particularly so for Mumsnet (Pedersen and Smithson 2010). For the purposes of the current paper Mumsnet therefore offered a promising site to find relevant discussions, bearing in mind however that the Mumsnet population are distinctive in relation to the whole population of Internet users (more likely to be female, in the 25 to 44 age groups, have children and be educated to graduate level than the general Internet population according to www.alexa.com) and by implication also a biased sample of the population as a whole (Dutton and Blank 2011).

I used the advanced search facility on the Mumsnet site to focus on message threads in the calendar year 2010 which featured either nits or lice in the subject of the thread. The intention 
was to focus on discussions which shared advice about how to deal with headlice infestation, rather than collecting all passing references to headlice made in the context of other conversations. A full calendar year was used in order to allow for any cycles either in the prevalence of headlice (sometimes held to be more common in warm weather), in their detection in children (often felt to be related to the school year) or in the frequency of use of Mumsnet according to the other demands of the domestic and working life of its users. The search was restricted to a single year because headlice treatment has been a changing picture in recent years as new evidence emerges and new treatments come onto the market. Focusing on one year (and in particular, one in which little changed in terms of available treatments) meant that a similar backdrop of formal knowledge and available treatments prevailed for all of the data. All of the resulting threads were copied into word processor documents, except where there was no obvious link to headlice (irrelevant threads mentioned guinea pig lice and poultry lice, plus mis-spellings of nit for not). This process produced 62 relevant discussion threads of varying lengths (2 - 85 messages) which mentioned lice or nits in the title: a total of 1127 messages. These were uploaded to NVivo qualitative data analysis software and subjected to an iterative thematic analysis. Each of the proposed remedies was coded individually, as were emergent themes such as risks, treatment failure, emotions, parenting expectations, sources of expertise and school policy.

Table 1 shows a full list of the messages threads included in the dataset. The majority of the threads (36 out of 62) lasted less than two days. Table 2 summarises the length of threads according to the subject area of the Mumsnet discussion forums in which the thread was placed. The majority of the threads were placed in the Children's Health subject area (32) or General Health (8). These health-related threads mainly consisted of fairly short exchanges of advice, both in duration and in number of messages (averaging 10.7 messages for Children's Health and 10.5 messages for General Health). Some threads extended for many more 
messages, particularly those within the “Am I being unreasonable?” debating area of the Mumsnet discussion forums, which within this dataset had an average length of 54.8 messages. The dataset thus contains a mixture of short advice-giving interactions focused around tips and techniques for prevention and eradication and extended debate on concerns around policies, practices and conflicts between different approaches.

Participation in both advice and debate was distributed quite evenly across the 567 unique nicknames who participated as Table 3 shows. All 62 threads were started by distinct nicknames, with the exception of three identical threads begun in error by one nickname and two identical threads similarly begun in error by another. 487 nicknames only appeared in a single thread, and the maximum number of threads in which any nickname appeared was six. There was little evidence, therefore, of any participants setting themselves up as experts giving advice on headlice across multiple threads, apparently contradicting O’Connor’s (2009) assumption that key opinion-formers will emerge in apomediation processes ${ }^{\mathrm{i}}$. Few participants choose to reveal demographic information. Within discussions participants were predominantly self-identified as mothers, although there was occasional input from fathers. Those who took part in discussions represented themselves as the ones who put the effort into evaluating and carrying out treatments. Although this gendering of responsibility was largely implicit, the dataset contained one extended discussion consisting largely of criticisms (in his absence) of a male partner who failed to accept responsibility for headlice combing in the face of his female partner's indisposition.

Before beginning the data sampling, permission was sought from and granted by Mumsnet to make use of the forums in this way. Permission was not sought from the individual participants in the discussion. The discussions on Mumsnet are publicly available on the Internet, and indeed consciousness of this publicness is a feature of the site for many users (Skea et al. 2008; Gambles 2010; Pedersen and Smithson 2010). However this consciousness 
of being in public does not necessarily mean that users would wish to be an individual focus of research and commentary without their consent. The analysis presented here is an aggregate which draws attention to prevailing themes, rather than attending to the practices of any individual user and thus might be considered to pose a low risk to those individuals. Direct quotations have been used sparingly and any that are used adapted to obviate the risk of identifying the author by searching, whilst retaining the sense of the original. Although Mumsnet users choose nicknames which generally obscure their real life identity, no nicknames of users have been included in the text, as nicknames may have a value for their users in terms of their online reputation. This is a more cautious stance than taken by Pedersen and Smithson (2010) and Skea et al (2008) in their use of Mumsnet data, and more in line with the approach taken by Holt (2011) in her analysis of parents’ online discussions of experiences of violence from their children.

\section{Emergent themes in the everyday science of headlice}

\section{Emotional registers and the risks of infestation}

The key emotion associated with the discovery of headlice was disgust. Contributors expressed their feelings with liberal use of exclamation marks, and gave descriptions of affected children as "riddled” and “crawling”, and of the lice themselves as “yuck”, “vile” “boaksome”, “revolting” and “minging”. Contributors frequently spoke of itching just thinking about lice (a condition formally known as psychogenic itch, which readers of this paper may also currently be experiencing). Infestation was largely treated as an inevitable aspect of childhood, and its treatment as an unavoidable, if irksome and frustrating, responsibility of parenthood. Only where infestations had spread to their own heads did contributors speak in terms suggestive of shame, referencing the mortification attendant on 
having headlice discovered by a hairdresser, or the unromantic nature of needing to have one’s hair combed for lice by a partner.

As described above, the majority of the message threads in the dataset positioned headlice as an issue of Children's Health or General Health, within the hierarchy of Mumsnet discussion topics. There was, however, little overt specification of health risks attendant on headlouse infestation and the dataset contained little usage of formal medical sources to support any claims of a risk to health. The emotional register of disgust provided much of the impetus for treatment, and defined to a large extent the risks that infestation was thought to pose to children. One contributor's suggestion that the faeces of lice were toxic was ridiculed, although in this rare case the ridicule was countered with a precise reference to an article in the British Medical Journal. In other cases suggestions that children might itch so much that they scratched themselves sore were accepted on the basis of anecdotal evidence (or at least went unchallenged in the public forum) despite experiences to the contrary described in other discussion threads, which held that children could be infested by lice and show no signs of itching. While the itching itself might be unpleasant, discussion of this was often packaged with concerns that children's schoolwork might be affected as they were distracted by itching, or they might be ostracised by schoolmates.

The disgust associated with headlice, the expectation of itching and the formulation of risks as associated with school performance and acceptance in social settings, positioned treatment of lice as a feature of responsible parenthood. Participants in these discussions were aware that other parents might be more tolerant of repeated infestations or take a more relaxed approach to treatment, but found this unacceptable for them. Within this context, adopting the identity of a responsible parent entailed accepting a perceived imperative to treat, and 
furthermore, to do so in a manner both effective and involving minimal risk to those treated. Parents in the Mumsnet discussions sampled found treatment laborious and repetitive, particularly where their evaluations of risk and cost led them to favour physical removal by combing, but many presented this labour as an inevitable and appropriate aspect of parenthood.

\section{Mechanisms of action}

Many of the discussion threads in the dataset were initiated by contributors asking for advice on effective treatments for headlice, either because they had just found them in their own child for the first time or because they had been warned by a school or nursery that their child may have been in contact with them. The advice which resulted was largely framed as offering support from personal experience, both in sharing the emotional register of horror, frustration and disgust and in offering experiences of what worked. Where physical removal was being practiced most of those offering advice said that eggs needed to be removed in addition to live lice, if treatment was to be effective in the long term. Their direct experience was of eggs that were visible and intransigent, attached firmly to hair and posing an ongoing threat, although there was little discussion of the important distinction between egg cases left behind after the hatching of the louse and still-viable eggs that might yet hatch out lice. The visual sign of the egg or egg case remaining attached to the hair served as an uncomfortable reminder of the infestation and was usually enough to prompt action.

Participants were often unclear as to whether various treatments, including physical combing, insecticides and silicone-based treatments had any effect on the viability of eggs that might be left in the hair. In the face of the felt imperative to do anything possible to treat an infestation there was widespread acceptance that repeat treatments would be needed to cater 
for eggs left behind by an initial treatment. In many cases a seven-day interval between repeat usage of lotions was promoted, but without any evidence justifying this specific interval beyond the recommendations from manufacturers of branded products. In fact, the seven-day interval between treatments, it is not uncontroversial: the "bug busting" method (www.chc.org) promotes a regime of re-combing based on a much more variable assessment of the life cycle duration (Takano-Lee et al. 2003). Where physical removal was practiced there was wide variability in the intervals which contributors recommended between combing, including twice daily until no further lice were seen, every three days for several weeks and two sessions one week apart. Some more complex regimes were suggested, such as combing daily for three days, twice daily for six days, then every three days until the $21^{\text {st }}$ day (although the contributor did qualify this advice with IIRC, meaning "if I remember correctly”).

Knowledge of the life cycle was, therefore, widely held to be important in knowing when and how to treat, but in practice there was wide variation in judgments of what exactly the life cycle was and how that impacted on the timing of combing, and participants made little use of any formal references or outside sources to justify their knowledge of the life cycle. There was also considerable variation in opinions as to whether headlice could live for any length of time away from the human body, and consequent divergence of advice on whether treatment should be accompanied by washing bedding, bagging up soft furnishings or placing unwashable items in the freezer. Non-specific reference was made to the official view that headlice cannot live away from the human host for any significant period of time, but this was questioned by some participants on the basis of their own experience or home-based observations of trials with captured lice. 
There was little overt disagreement or argument in the forums relating to the practice of headlice treatment. Occasionally more extreme statements would be challenged, but participants largely allowed one another’s advice to stand unquestioned. Occasionally participants mentioned checking up on advice they were offering themselves, for example by googling on the effectiveness of freezing clothing to kill any headlice left on them. Behind the advice offered in the forum there may, therefore, be considerably more use of other sources of expertise than is readily apparent. A feature of Mumsnet discussions is the emphasis on the parent as expert on their own experiences, and in this light, discussions on the treatment of headlice favoured anecdotal evidence and tolerated a high degree of internal contradiction on statements about the basic science underlying treatment. This does not mean however that participants are not using more formal information sources to inform the actions that they subsequently take.

Alongside a general lack of detail on the biology and life cycle of headlice in relation to treatment there was also no detailed justification for why various substances promoted as lice repellents might work. Tea tree oil was widely favoured as a substance that lice “just don't like” without further articulation of a mechanism. Neem oil was proposed as an agent that "stops them breeding” or "rots them from inside" and coconut oil as a substance that lice find toxic or are suffocated by. Judgments about whether repellents worked were largely anecdotal, although one participant noted that this was hardly a reliable test, since as we all know the absence of elephants in everyday experience does not in itself imply that the elephant repellent one is wearing works. There was some generalised trust in a system of research, trials and testing, manifested in questions around whether repellents had been subjected to proper trials and allusions to research that had, the participant stated, found nit nurses to be ineffective in controlling outbreaks. Alongside specific mentions of research as 
productive of reliable information went a generalised expectation that truth would out, including a suggestion from one contributor that one should be cautious of proposed miracle cures because if something were that good one would have heard about it in the media.

\section{Risk in relation to treatments}

The risks of headlice infestation were viewed as largely emotional and social. Some treatments were also thought of as carrying potential physical risks, and this sense of treatment as a risky practice informed the decisions that participants described. Physical removal by combing was largely thought of as risk-free except in so far as the practice of combing caused distress to the child (particularly notable in the case of some parents of children with special needs), or was damaging to the hair. "Natural” remedies such as tea-tree oil were largely represented as risk-free, despite the publication of some widely circulated scientific articles questioning their safety (for example Henley et al. 2007). The main discourse of risk, as far as treatments were concerned, centred on putting “chemicals” on a child's head, particularly a very young child. This concern was largely undifferentiated, in that it was more often applied to all branded treatments, only occasionally directed at a specific brand-name, and nowhere in the dataset directed at a specific pesticidal agent. Participants only rarely differentiated explicitly between silicone-based non-pesticidal treatments and more conventional pesticides. A memory of products that had previously been available and subsequently withdrawn from sale informed some attitudes of caution.

Although potentially risky, “chemicals” were also often thought of as stronger or more effective, and thus some participants presented themselves as justified in using them if other approaches had failed, or if circumstances dictate a swift response. In a context which held that any risk to children should be avoided wherever possible, it appeared that some additional justification was needed in order to continue to position oneself as a responsible 
parent and yet use potentially risky agents. The expectation of stronger, more effective treatment via pesticidal treatments was, however, often challenged by participants who held that laborious, repeated combing was the only guaranteed route, using bitter experience as their authority to make that judgment.

If “chemicals” were discussed in a generic sense which did not distinguish particular agents, the same was not true of branded products. Brand-names were used as an economical way of passing information between participants on effective treatments. Indeed, some responses to requests for advice on what to do in face of infestation consisted simply of a terse remark such as "Use this" accompanied by a link to a site where the product might be bought. The brand was a short-hand, but his does not mean, however, that branded products were always unproblematic markers of credibility, as Eysenbach (2008a) suggests . Instead, brands themselves could be said to be apomediated, as a lot of discussion revolved around varied experiences of using products and how to negotiate problems associated with their use. One concern associated with silicone-based treatments, for example, revolved around the difficulty of washing the hair to remove the product afterwards. Failure to remove the product was seen as carrying a stigma through appearing at school having clearly been treated because of "wet hair” appearance. Participants exchanged tips about how to remove the product most effectively.

\section{Sources of expertise}

Discussants made little overt use of formal literature, nor did they reference sources of official information, preferring to rely on personal narratives (Lindholm 2010) or branded products, at least within the observable discussions. Many presented themselves as involved in an individual quest to find a solution that worked, largely without assistance from 
healthcare professionals. Within the forums, contacts with doctors were described largely in the context of acquiring prescriptions for branded products. Participants presented themselves as having recourse to the doctor in order to acquire a prescription which would entitle them to be issued the product free of charge by the pharmacist, and spoke of frustration when the doctor's preferred treatment did not accord with their own views. Doctors were as often the villains as the heroes (Wagner-Egger et al. 2011) in these online narratives, particularly in relation to the question of free prescriptions, as in addition to risk, one of the key concerns which arose about treatment was its cost. Specific branded products ${ }^{\mathrm{ii}}$ were often approved and trusted but found to be expensive, and this made the role of healthcare professionals as gatekeepers to free treatments particularly significant but did not mean that they were represented as trusted sources of advice over and above personal experience.

Hairdressers acted as a different kind of gatekeeper, in that a visit to the hairdresser was often either the occasion of diagnosis or was the occasion for participants expressing concern that they needed to be clear of all signs of infestation before visiting a hairdresser. Hairdressers might be in the position of telling customers that they had found lice, but they were not in the position of recommending remedies. Rather than stopping to discuss the matter with a hairdresser, participants described themselves as leaving in a hurry due to embarrassment. Parents in the Mumsnet forum largely acted as informal risk communicators (Rickard 2011) for one another in their role as parents with experience of headlice, without reliance on professionals in any capacity.

\section{Discussion and conclusion}

Mumsnet discussions provide a distinctive social environment where detailed discussion of headlice eradication techniques is sanctioned. This frankness of discussion contrasts strongly 
with the taboo that often surrounds face-to-face discussion of the topic, even between parents who are friends. This is a highly emotive topic, and the eradication of headlice is here strongly linked to ideas about adequate parenting. Discussions confirmed survey-based evidence that many parents found remedies difficult to apply (Parison et al. 2008), but stressed in addition that this was not for the want of trying. Many messages referred directly to the need to take the initiative and find out what to do about headlice. Within this context, one aspect of being appropriately informed involved being able to talk about eggs and about treatment regimes in terms of basic details of the life cycle. Formal scientific expertise, however, played little part in presenting oneself as appropriately informed. We cannot, however, judge from observing the site alone to what extent individual parents may be reviewing both discussion forums and formal advice sites in order to arrive at an informed course of action, and as Eysenbach (2008a) suggests, it is likely that individuals will use both, and may shift their preference between them at different points. That formal advice sites feature little in the discussions suggests that participants might be not be drawing upon them, but this could also simply be because the dominant style of discussion in Mumsnet does not favour such overt references.

In the visible dynamics of the forum, then, formal intermediaries were side-lined and the process of information exchange appeared much like apomediation (Eysenbach 2008a; Eysenbach 2008b). Those offering advice did so from a position of authority largely based on their own experiences, in potential contrast to the survey evidence on headlice treatment which suggests that parents feel ill-informed to make treatment choices (Silva et al. 2008; Frankowski et al. 2010) and in similar style to the presumed authority of individual bodily experience which Leibing (2009) found among online discussions between patients. There was an overwhelming reliance on brands as a substitute for detailed discussion of treatment 
mechanisms, but these brands themselves were subject to processes of filtering and interpretation characteristic of apomediation (Eysenbach 2008b). Mention of risk arose most commonly in the context of one's children being stigmatized or performing poorly in school, but was also associated with pesticidal treatments. Even without detailed exposition of what those risks might be, the use of pesticides was often seen as unjustified given that a physical mode of removal is available. The labour, time and dedication needed to effect a cure via physical removal was thus portrayed as one of the necessary costs of responsible parenting.

The anecdotal format of advice given on Mumsnet contrasted greatly with the more formalised, evidence-based approach taken by intermediaries such as public health advice sites and by the sites maintained by manufacturers of branded products. Participants constructed a collective in which personal experience was evaluated on a par with, and often favoured over, formal scientific knowledge (Irwin and Wynne 1996). They filtered what they knew of official advice through their own perceptions of what was practical for them to achieve, as did the sheep farmers discussed by Wynne (1992). This everyday knowledge of headlice is inseparable from salient identity of parent and the context of its expression, which in this case is the Mumsnet discussion forums. Salient identities shape discourse about science (Wynne 2008) and within Mumsnet a particular form of “personal public” emerges that positions valued advice as being given in public, as a parent (Gambles 2010). In part this involves sympathetically orienting to other participants as parents and valuing their experiences, leading to emergence of a genre of "headlice talk" similar in style to the discussion of concerns about the MMR vaccinations discussed by Poltorak et al (2005) where respecting other parents’ choices can take precedence over evaluation of scientific evidence. 
The processes of apomediation observed in online headlice discussions can be seen to involve the co-construction of context, knowledge and salient identity. Whilst apomediation (Eysenbach 2008a; Eysenbach 2008b) is a useful collective term for certain kinds of information exchange practice which replace traditional expertise with peer recommendations, in a sense public understanding of science has always been apomediated, and the term on its own fails fully to capture the situated nature of these practices and the intertwined construction of contexts and salient identities through which standards of credibility are established and ultimately what counts as information for that context emerges. Practices of apomediation produce contextual knowledges (Irwin 1995) and thus it can be seen that existing perspectives on the contextual nature of public engagement with science remain useful in understanding the apparently new dynamics of expertise occasioned by Web 2.0 (O'Reilly 2005). 
Table 1. Mumsnet message threads analysed

\begin{tabular}{|c|c|c|c|}
\hline Subject area $^{\text {iii }}$ & Thread title & $\begin{array}{l}\text { Number } \\
\text { of } \\
\text { messages }\end{array}$ & Duration \\
\hline Children's health & Head lice & 2 & $25 / 5 / 10-25 / 5 / 10$ \\
\hline Children's health & Head lice question & 4 & $20 / 8 / 10-20 / 8 / 10$ \\
\hline Children's health & Lice, need advice. & 8 & $31 / 10 / 10-1 / 11 / 10$ \\
\hline Children's health & $\begin{array}{l}\text { What is the best lice } \\
\text { treatment }\end{array}$ & 10 & $1 / 11 / 10-11 / 11 / 10$ \\
\hline Children's health & Bloody Head Lice!!! 8-( & 10 & $30 / 3 / 10-5 / 4 / 10$ \\
\hline Children's health & head lice in secondary school & 7 & $15 / 5 / 10-15 / 5 / 10$ \\
\hline General health & Head lice again & 6 & $8 / 6 / 10-8 / 6 / 10$ \\
\hline Children's health & argh!! head lice are back & 15 & $7 / 7 / 10-8 / 7 / 10$ \\
\hline General health & Chronic head lice & 18 & $\begin{array}{l}\text { 2/8/10-4/8/10 (16 } \\
\text { messages) then } \\
23 / 8 / 10(2 \\
\text { messages) }\end{array}$ \\
\hline Parenting & $\begin{array}{l}\text { Head lice, what is the } \\
\text { definitive treatment? }\end{array}$ & 33 & $\begin{array}{l}21 / 9 / 10-26 / 9 / 10(31 \\
\text { messages) then } \\
21 / 2 / 11(2 \\
\text { messages) }\end{array}$ \\
\hline Children's health & $\begin{array}{l}\text { Head lice prevention tips } \\
\text { please }\end{array}$ & 17 & $11 / 1 / 10-15 / 1 / 10$ \\
\hline General health & $\begin{array}{l}\text { What is the best treatment for } \\
\text { head lice? }\end{array}$ & 21 & $\begin{array}{l}\text { 21/7/10-22/7/10 (12 } \\
\text { messages) then } \\
\text { 20/9/10-20/9/10 (9 } \\
\text { messages) }\end{array}$ \\
\hline Children's health & bloody hell, head lice! Help!! & 17 & $17 / 7 / 10-17 / 7 / 10$ \\
\hline Children's health & $\begin{array}{l}\text { Head lice! Anyone used } \\
\text { Hedrin } 1 \text { hour? }\end{array}$ & 20 & $\begin{array}{l}\text { 22/9/10-27/9/10 (18 } \\
\text { messags) then } \\
9 / 11 / 10-10 / 11 / 10(2 \\
\text { messages) }\end{array}$ \\
\hline General health & $\begin{array}{l}\text { Effective perfume free head } \\
\text { lice treatments? }\end{array}$ & 11 & $17 / 5 / 10-22 / 5 / 10$ \\
\hline $\begin{array}{l}\text { Childminders, nannies, } \\
\text { au pairs etc }\end{array}$ & $\begin{array}{l}\text { Head lice, would you send a } \\
\text { child home? }\end{array}$ & 59 & $17 / 9 / 10-3 / 10 / 10$ \\
\hline Multicultural families & $\begin{array}{l}\text { Help possible Head lice in } \\
\text { afro hair }\end{array}$ & 10 & $\begin{array}{l}13 / 4 / 10-15 / 4 / 10(7 \\
\text { messages) then } \\
6 / 6 / 10(1 \text { message }) \\
\text { then } 6 / 3 / 10(2\end{array}$ \\
\hline
\end{tabular}




\begin{tabular}{|c|c|c|c|}
\hline & & & messages) \\
\hline Children's health & $\begin{array}{l}\text { Blooming head lice..advice } \\
\text { please. }\end{array}$ & 23 & $\begin{array}{l}\text { 21/8/10-23/8/10 (17 } \\
\text { messages) then } \\
\text { 23/6/11-24/6/11 (5 } \\
\text { messages) then } \\
6 / 3 / 12 \text { ( } 1 \text { message) }\end{array}$ \\
\hline $\begin{array}{l}\text { Am I being } \\
\text { unreasonable? }\end{array}$ & $\begin{array}{l}\text { to think that head lice } \\
\text { treatment should be free? }\end{array}$ & 85 & $23 / 4 / 10-24 / 4 / 10$ \\
\hline Primary education & $\begin{array}{l}\text { What's your school policy on } \\
\text { head lice info? }\end{array}$ & 30 & $\begin{array}{l}\text { 9/9/10-10/9/10 (20 } \\
\text { messages) then } \\
\text { 13/9/11-15/9/11 (10 } \\
\text { messages) }\end{array}$ \\
\hline General health & $\begin{array}{l}\text { Nitty Gritty head lice } \\
\text { treatment kills head lice } \\
\text { EGGS?? Too good to be } \\
\text { true!? }\end{array}$ & 2 & $19 / 12 / 10-19 / 12 / 10$ \\
\hline Pregnancy & $\begin{array}{l}\text { Can i use Full Mark Head } \\
\text { Lice Solution? }\end{array}$ & 6 & $7 / 11 / 10-7 / 11 / 10$ \\
\hline Children's health & $\begin{array}{l}\text { Head Lice - A Definitive List } \\
\text { of What I Need Please! }\end{array}$ & 21 & $6 / 12 / 10-8 / 12 / 10$ \\
\hline Children's health & $\begin{array}{l}\text { Ahh!! head lice. Please, what } \\
\text { am I doing wrong? }\end{array}$ & 7 & $13 / 2 / 10-14 / 2 / 10$ \\
\hline Children's health & $\begin{array}{l}\text { when do i send my dds back } \\
\text { to school.....with head } \\
\text { lice???? }\end{array}$ & 8 & 23/3/10-23/3/10 \\
\hline What would you do? & $\begin{array}{l}\text { Haircut tomorrow and I've } \\
\text { found some lice do I cancel } \\
\text { or hope to get all the buggers } \\
\text { out? }\end{array}$ & 15 & $14 / 5 / 10-15 / 5 / 10$ \\
\hline $\begin{array}{l}\text { Am I being } \\
\text { unreasonable? }\end{array}$ & $\begin{array}{l}\text { To think kids with terrible } \\
\text { cases of head lice should be } \\
\text { kept home from school... }\end{array}$ & 41 & $25 / 6 / 10-26 / 6 / 10$ \\
\hline Product tests/feedback & $\begin{array}{l}\text { Does your child have head } \\
\text { lice right now? Would you } \\
\text { like to try the award winning } \\
\text { Nitty Gritty Comb, and then } \\
\text { add feedback on Mumsnet? }\end{array}$ & 42 & $10 / 5 / 10-20 / 5 / 10$ \\
\hline $\begin{array}{l}\text { Am I being } \\
\text { unreasonable? }\end{array}$ & $\begin{array}{l}\text { To bar my child from seeing } \\
\text { her cousin as she has been } \\
\text { infected with head lice at } \\
\text { least } 4 \text { times from her now. }\end{array}$ & 53 & $\begin{array}{l}\text { 25/3/10-26/3/10 (47 } \\
\text { messages) then } \\
\text { 9/4/10-11/4/10 (6 } \\
\text { messages) }\end{array}$ \\
\hline Children's health & Nits? & 6 & 26/9/10 - 3/10/10 \\
\hline Primary education & $\underline{\underline{\text { nits }}}$ & 14 & $30 / 9 / 10-30 / 9 / 10$ \\
\hline Children's health & Nits!!!!! & 18 & $4 / 5 / 10-5 / 5 / 10$ \\
\hline Children's health & Bloody nits! & 7 & $23 / 5 / 10-3 / 6 / 10$ \\
\hline
\end{tabular}




\begin{tabular}{|c|c|c|c|}
\hline $\begin{array}{l}\text { Am I being } \\
\text { unreasonable? }\end{array}$ & $\underline{\text { Nits - a rant about DH }}$ & 29 & $7 / 10 / 10-8 / 10 / 10$ \\
\hline Children's health & Are nits old hat? & 4 & $17 / 11 / 10-23 / 11 / 10$ \\
\hline Primary education & New to Nits Which Product & 4 & $4 / 1 / 10-4 / 1 / 10$ \\
\hline Primary education & New to Nits Which Product & 23 & $4 / 1 / 10-6 / 1 / 10$ \\
\hline Primary education & New to Nits Which Product & 5 & $4 / 1 / 10-4 / 1 / 10$ \\
\hline$\underline{\text { Politics }}$ & Bring back the nit nurse! & 3 & $23 / 1 / 10-23 / 1 / 10$ \\
\hline Children's health & Help - NITS - eugghh! & 6 & $22 / 4 / 10-23 / 4 / 10$ \\
\hline Children's health & Itchy scalp - but no nits & 5 & $13 / 8 / 10-14 / 8 / 10$ \\
\hline Children's health & $\begin{array}{l}\text { Tips badly needed for nit } \\
\text { removal! }\end{array}$ & 30 & $22 / 12 / 10-26 / 12 / 10$ \\
\hline Children's health & $\begin{array}{l}\text { First time dealing with nits - } \\
\text { help }\end{array}$ & 2 & $28 / 3 / 10-28 / 3 / 10$ \\
\hline Children's health & $\begin{array}{l}\text { First time dealing with nits - } \\
\text { help }\end{array}$ & 4 & $28 / 3 / 10-30 / 3 / 10$ \\
\hline Children's health & Nits in boys hair - shave it??? & 6 & $1 / 7 / 10-1 / 7 / 10$ \\
\hline Behaviour/development & $\begin{array}{l}\text { shaving girl's head ot get rid } \\
\text { of nits? }\end{array}$ & 80 & $\begin{array}{l}\text { 29/8/10-2/9/10 (76 } \\
\text { messages) then } \\
9 / 9 / 10-10 / 9 / 10 \text { (3 } \\
\text { messages) then } \\
7 / 10 / 10 \text { ( } 1 \text { message) }\end{array}$ \\
\hline General health & $\begin{array}{l}\text { WHY is one of my children } \\
\text { always catching nits????? }\end{array}$ & 15 & $\begin{array}{l}14 / 9 / 10-15 / 9 / 10(13 \\
\text { messages }) \text { then } \\
20 / 9 / 10(2 \\
\text { messages })\end{array}$ \\
\hline Children's health & $\begin{array}{l}\text { What is the best way of } \\
\text { treating and preventing nits? }\end{array}$ & 12 & $14 / 10 / 10-16 / 10 / 10$ \\
\hline $\begin{array}{l}\text { Am I being } \\
\text { unreasonable? }\end{array}$ & $\begin{array}{l}\text { to want more than a } 3 \text { week } \\
\text { gap with no nits? }\end{array}$ & 44 & $10 / 1 / 10-11 / 1 / 10$ \\
\hline Special needs: children & $\begin{array}{l}\text { How do you deal with nits } \\
\text { with an ASD child? }\end{array}$ & 22 & $1 / 3 / 10-2 / 3 / 10$ \\
\hline Children's health & $\begin{array}{l}\text { Nitty gritty nit repellant - } \\
\text { does it work? }\end{array}$ & 2 & 22/4/10-22/4/10 \\
\hline Children's health & $\begin{array}{l}\text { How long do nits live for } \\
\text { (not in hair)? }\end{array}$ & 6 & $17 / 6 / 10-17 / 6 / 10$ \\
\hline Children's health & $\begin{array}{l}\text { Nits- what EXACTLY am I } \\
\text { looking for }\end{array}$ & 12 & 7/7/10-7/7/10 \\
\hline Children's health & The seven week itch. Need & 11 & $20 / 8 / 10-23 / 8 / 10$ \\
\hline
\end{tabular}




\begin{tabular}{|c|c|c|c|}
\hline & $\begin{array}{l}\text { help from some NITS } \\
\text { veterans }\end{array}$ & & \\
\hline Children's health & $\begin{array}{l}\text { Nit prevention, ways of } \\
\text { reducing the chances of } \\
\text { catching the little pests. }\end{array}$ & 10 & $27 / 9 / 10-28 / 9 / 10$ \\
\hline Children's health & $\begin{array}{l}\text { Can't I comb nit eggs out } \\
\text { then? }\end{array}$ & 12 & 19/1/10-20/1/10 \\
\hline $\begin{array}{l}\text { Am I being } \\
\text { unreasonable? }\end{array}$ & $\begin{array}{l}\text { to not want to hang out with } \\
\text { family who have really really } \\
\text { bad nits? }\end{array}$ & 77 & $22 / 1 / 10-26 / 1 / 10$ \\
\hline General health & $\begin{array}{l}\text { The nits are gone, but I can't } \\
\text { get rid of the eggs..... }\end{array}$ & 9 & $20 / 5 / 10-20 / 5 / 10$ \\
\hline Pregnancy & $\begin{array}{l}\text { Headlice, nits in pregnancy } \\
27 \text { wks, pls help me! }\end{array}$ & 11 & $29 / 6 / 10-1 / 7 / 10$ \\
\hline Mumsnet campaigns & $\begin{array}{l}\text { Can we have a campaign to } \\
\text { bring back the nit nurse into } \\
\text { schools aswell please? }\end{array}$ & 5 & $5 / 1 / 10-6 / 1 / 10$ \\
\hline Children's health & $\begin{array}{l}\text { DS1 has nits, what do I do, } \\
\text { what produts to use? }\end{array}$ & 20 & $\begin{array}{l}1 / 7 / 10-4 / 7 / 10(17 \\
\text { messages) then } \\
12 / 8 / 10-13 / 8 / 10(3 \\
\text { messages) }\end{array}$ \\
\hline General health & $\begin{array}{l}\text { How the hell do I get rid of } \\
\text { nits in } 2.5 \text { yr old DS's hair? }\end{array}$ & 12 & $20 / 6 / 10-21 / 6 / 10$ \\
\hline
\end{tabular}


Table 2. Distribution of threads across subject areas

\begin{tabular}{|l|l|l|}
\hline Subject area & Number of threads & $\begin{array}{l}\text { Average number of } \\
\text { messages per thread }\end{array}$ \\
\hline Children's health & 32 & 10.7 \\
\hline General health & 8 & 10.5 \\
\hline Am I being unreasonable? & 6 & 54.8 \\
\hline Primary education & 5 & 15.2 \\
\hline Pregnancy & 2 & 8.5 \\
\hline Behaviour/development & 1 & 80 \\
\hline $\begin{array}{l}\text { Childminders, nannies, au } \\
\text { pairs etc }\end{array}$ & 1 & 59 \\
\hline Multicultural families & 1 & \\
\hline Mumsnet campaigns & 1 & 10 \\
\hline Parenting & 1 & 5 \\
\hline Politics & 1 & 33 \\
\hline Product tests/feedback & 1 & 3 \\
\hline Special needs: children & 1 & 42 \\
\hline What would you do? & 1 & 22 \\
\hline
\end{tabular}


Table 3 Frequency of contribution to threads by nicknames

\begin{tabular}{|l|l|}
\hline $\begin{array}{l}\text { Number of threads within the dataset to } \\
\text { which a nickname posted messages }\end{array}$ & Number of nicknames \\
\hline 1 & 487 \\
\hline 2 & 61 \\
\hline 3 & 13 \\
\hline 4 & 5 \\
\hline 5 & 0 \\
\hline 6 & 1 \\
\hline & \\
\hline & Total: 567 \\
\hline
\end{tabular}




\section{References}

Budd, K. (2001) Assessing parenting competence in child protection cases: a clinical practice model. Clinical Child and Family Psychology Review 4(1): 1-18.

Burgess, I. (2009) The mode of action of dimeticone $4 \%$ lotion against head lice, Pediculus capitis. BMC Pharmacology 9(1): 3. http://www.biomedcentral.com/1471-2210/9/3

Burgess, I. F., C. M. Brown and P. N. Lee (2005) Treatment of head louse infestation with $4 \%$ dimeticone lotion: randomised controlled equivalence trial. BMJ 330(7505): 1423.

Chemist+Druggist. (2011) Category focus: Head lice and worming. Retrieved 4 December, 2010, http://www.chemistanddruggist.co.uk/news-content//article_display_list/FF3k/content/4249767/.

CKS. (2010) Head Lice. Retrieved 12/8/2010, http://www.cks.nhs.uk/headlice.

Daneback, K. and L. Plantin (2008) Research on parenthood and the Internet: themes and trends

Cyberpsychology: Journal of Psychosocial Research on Cyberspace 2, Article 2 http://cyberpsychology.eu/view.php?cisloclanku=2008110701\&article=2.

Dodds, R. E., E. Tseëlon and E. L. C. Weitkamp (2008) Making sense of scientific claims in advertising. A study of scientifically aware consumers. Public Understanding of Science 17(2): 211-230.

Dutton, W. H. and G. Blank (2011) Next generation users: the Internet in Britain. Oxford Internet Survey 2011 report Oxford: Oxford Internet Institute.

Eden, S. (2011) Food labels as boundary objects. Public Understanding of Science 20(2): 179-194. http://pus.sagepub.com/content/20/2/179.abstract

Eysenbach, G. (2008a) Credibility of health information and digital media: new perspectives and implications for youth. In Digital Media, Youth, and Credibility.. The John D. and Catherine T. MacArthur Foundation Series on Digital Media and Learning. Ed. M. J. Metzger and A. J. Flanagin. Cambridge, MA: MIT Press pp. 123-154.

Eysenbach, G. (2008b) Medicine 2.0: social networking, collaboration, participation, apomediation, and openness. Journal of Medical Internet Research 10(3): e22. http://www.pubmedcentral.nih.gov/articlerender.fcgi?artid=2626430

Falagas, M. E., D. K. Matthaiou, P. I. Rafailidis, G. Panos and G. Pappas (2008) Worldwide prevalence of head lice. Emerging Infectious Diseases 14(9): 1493-1494.

Frankowski, B. L., J. A. Bocchini, Jr, C. o. S. Health and Committee on Infectious Diseases (2010) Head Lice. Pediatrics 126(2): 392-403.

Gambles, R. (2010) Going public? Articulations of the personal and political on Mumsnet.com. In Rethinking the Public: Innovations in Research, Theory and Politics. Ed. N. Mahony, J. Newman and C. Barnett. London: Sage pp. 29-41.

Gordon, S. C. (2007) Shared vulnerability: a theory of caring for children with persistent head lice. The Journal of School Nursing 23(5): 283-292.

Hardey, M. (1999) Doctor in the house: the Internet as a source of lay health knowledge and the challenge to expertise. Sociology of Health \& IIIness 21(6): 820-835.

Harris, J., J. G. Crawshaw and S. Millership (2003) Incidence and prevalence of head lice in a district health authority area. Communicable Disease and Public Health 6(3): 246-249.

Henley, D. V., N. Lipson, K. S. Korach and C. A. Bloch (2007) Prepubertal gynecomastia linked to lavender and tea tree oils. New England Journal of Medicine 356(5): 479-485.

Heukelbach, J. and U. S. Ugbomoiko (2011) Knowledge, attitudes and practices regarding head lice infestations in rural Nigeria. Journal of Infection in Developing Countries 5 http://www.jidc.org/index.php/journal/article/view/21918306.

Holt, A. (2011) 'The terrorist in my home': teenagers' violence towards parents - constructions of parent experiences in public online message boards. Child \& Family Social Work 16(4): 454463.

Irwin, A. (1995) Citizen science: a study of people, expertise and sustainable development: Routledge. 
Irwin, A., A. Dale and D. Smith (1996) Science and Hell's kitchen: the local understanding of hazard issues. In Misunderstanding Science? The public reconstruction of science and technology. Ed. A. Irwin and B. Wynne. Cambridge: Cambridge University Press pp. 47-64.

Irwin, A. and B. Wynne, Eds. (1996) Misunderstanding Science? The public reconstruction of science and technology. Cambridge, Cambridge University Press.

Lambert, H. and H. Rose (1996) Disembodied knowledge? Making sense of medical science. In Misunderstanding Science? The public reconstruction of science and technology. Ed. A. Irwin and B. Wynne. Cambridge: Cambridge University Press pp. 65-83.

Leibing, A. (2009) Lessening the evils, online: embodied molecules and the politics of hope in Parkinson's disease. Science Studies 22(2): 80-101.

Lindholm, L. (2010) "A little story, food for thought..." Narratives in advice discourse. In Discourses in Interaction. Ed. S.-K. Tanskanen, M.-L. Helsvuo, M. Johansson and M. Raitaniemi. Amsterdam: John Benjamins pp. 223-236.

Madge, C. and H. O'Connor (2006) Parenting gone wired: Empowerment of new mothers on the internet? Social \& Cultural Geography 7(2): 199-220.

Miah, A. and E. Rich (2008) The Medicalization of Cyberspace. Abingdon: Routledge.

O'Connor, D. (2009) Apomediation and the significance of online social networking. The American Journal of Bioethics 9(6-7): 25-27.

O'Reilly, T. (2005) What is Web 2.0? Design patterns and business models for the next generation of software. Retrieved 2011, 10 February, http://oreilly.com/web2/archive/what-is-web20.html.

Olowokure, B., H. Jenkinson, M. Beaumont and H. Duggal (2003) The knowledge of healthcare professionals with regard to the treatment and prevention of head lice. International Journal of Environmental Health Research 13(1): 11 - 15. http://www.informaworld.com/10.1080/0960312021000063250

Parison, J. C., R. Speare and D. V. Canyon (2008) Uncovering family experiences with head lice: the difficulties of eradication. The Open Dermatology Journal 2: 9-17.

Pedersen, S. and J. Smithson (2010) Membership and activity in an online parenting community. In The Handbook of Research on Discourse Behavior and Digital Communication: Language Structures and Social Interaction. Ed. R. Taiwo. Hershey, PA: IGI Global pp. 88-103.

Poltorak, M., M. Leach, J. Fairhead and J. Cassell (2005) 'MMR talk' and vaccination choices: an ethnographic study in Brighton. Social Science \& Medicine 61(3): 709-719.

Rickard, L. N. (2011) In backyards, on front lawns: examining informal risk communication and communicators. Public Understanding of Science 20(5): 642-657.

Sarkadi, A. and S. Bremberg (2004) Socially unbiased parenting support on the Internet: a crosssectional study of users of a large Swedish parenting website. Child: Care, Health \& Development 31(1): 43-52.

Silva, L., R. de Aguiar Alencar and N. G. Madeira (2008) Survey assessment of parental perceptions regarding head lice. International Journal of Dermatology 47(3): 249-255.

Skea, Z. C., V. A. Entwistle, I. Watt and E. Russell (2008) 'Avoiding harm to others' considerations in relation to parental measles, mumps and rubella (MMR) vaccination discussions - An analysis of an online chat forum. Social Science \& Medicine 67(9).

Takano-Lee, M., K. S. Yoon, J. D. Edman, B. A. Mullens and J. M. Clark (2003) In vivo and in vitro rearing of Pediculus humanus capitis (Anoplura: Pediculidae). Journal of Medical Entomology 40(5): 628-635.

Teale, A., H. Diggal, W. Phillips, M. Beaumont, A. Pepperman and K. Kay (2008) Head Lice: Evidence based guidelines based on the Stafford report London: Public Health Medicine Environmental Group. http://www.phmeg.org.uk

Wagner-Egger, P., A. Bangerter, I. Gilles, E. Green, D. Rigaud, F. Krings, C. Staerklé and A. Clémence (2011) Lay perceptions of collectives at the outbreak of the H1N1 epidemic: heroes, villains and victims. Public Understanding of Science 20(4): 461-476. 
Wagner, W. (2007) Vernacular science knowledge: its role in everyday life communication. Public Understanding of Science 16(1): 7-22.

Wynne, B. (1992) Misunderstood misunderstanding: social identities and public uptake of science. Public Understanding of Science 1(3): 281-304.

Wynne, B. (2008) Elephants in the rooms where publics encounter "science"?: A response to Darrin Durant, "Accounting for expertise: Wynne and the autonomy of the lay public". Public Understanding of Science 17(1): 21-33.

Zeyer, A. and W.-M. Roth (2011) Post-ecological discourse in the making. Public Understanding of Science Pre-published on February 23, 2011 as doi:10.1177/0963662510394949

'This only refers to overt dominance of discussion since it cannot be assumed that unique nicknames represent unique individuals. Name changing is a regular practice for many on Mumsnet, whether for jokes, to reflect significant events or to allow for a sensitive discussion to take place without being associated with one's regular nickname

ii Participants particularly recommended a distinctive branded comb and the silicone-based lotion.

iii The Subject Area denotes the pre-defined area of the Mumsnet discussion forums with which the user chose to associate their new thread. 